\title{
INTERVENTION IMPROVES RESTAURANT EMPLOYEES' \\ FOOD SAFETY COMPLIANCE RATES
}

\author{
Valerie K. Pilling \\ Laura A. Brannon \\ Carol W. Shanklin \\ Kevin R. Roberts \\ Betsy B. Barrett \\ Amber D. Howells
}

Valerie K. Pilling, M.S., Ph.D. Candidate in Psychology, Kansas State University, vpilling@ksu.edu, 492 Bluemont Hall, Kansas State University, 66506; Laura A. Brannon, Ph.D., Associate Professor of Psychology, Kansas State University, 1brannon@ksu.edu, 492 Bluemont Hall, Kansas State University, 66506; Carol W. Shanklin, Ph.D., R.D., Associate Dean of the Graduate School, Kansas State University, shanklin@ksu.edu, 103 Fairchild Hall, Kansas State University, 66506; Kevin R. Roberts, M.S., Ph.D. Candidate in Hotel, Restaurant, Institution Management \& Dietetics, Kansas State University, roberts@humec.ksu.edu, 104 Justin Hall, Kansas State University, 66506; Betsy B. Barrett, M.S., Ph.D. Associate Professor of Hospitality and Dietetics, ebb@ksu.edu, 107 Justin Hall, Kansas State University, 66506; Amber D. Howells, Graduate Student in Hotel, Restaurant, Institution Management \& Dietetics, Kansas State University, amberkstate@yahoo.com, 104 Justin Hall, Kansas State University, 66506. 


\section{INTERVENTION IMPROVES RESTAURANT EMPLOYEES' \\ FOOD SAFETY COMPLIANCE RATES}

\section{Paper Category: Research paper}

\section{Structured Abstract:}

Purpose. To investigate whether a simple intervention program based on the Theory of Planned Behavior targeting foodservice employees' perceived barriers to implementing food safety practices improves compliance with guidelines, when offered alone or in combination with ServSafe ${ }^{\circledR}$ training. Behaviors targeted included handwashing, use of thermometers, and proper handling of food and work surfaces.

Methodology. Four groups were compared: employees receiving only ServSafe ${ }^{\circledR}$ training, intervention alone, training and intervention, and no treatment. Employees completed a questionnaire assessing perceived barriers to practicing the targeted behaviors. Then, employees were observed in the production area for compliance with the behaviors.

Findings. Training or intervention alone was better than no treatment, but the training and intervention combination was most effective at improving employees' compliance with and perceptions of control over performing the behaviors.

Research Limitations/Implications. Research was limited to restaurant employees in three states, in only 31 of the 1298 restaurants originally contacted. Future research should identify barriers to other food safety practices and evaluate the effectiveness of these and other intervention strategies.

Practical Implications. ServSafe ${ }^{\circledR}$ food safety training can be enhanced with a simple intervention targeting foodservice employees' perceived barriers to food safety. Providing 
knowledge and addressing barriers are both important steps to improving food safety in restaurants.

Value. No previous research has used the Theory of Planned Behavior to target foodservice employees' perceived barriers to implementing food safety practices to increase compliance with food safety guidelines, nor has research attempted to improve the effectiveness of ServSafe ${ }^{\circledR}$ food safety training by adding an intervention.

Keywords: food safety, barriers, intervention, food safety training, ServSafe ${ }^{\circledR}$, food handling 


\section{INTERVENTION IMPROVES RESTAURANT EMPLOYEES’ \\ FOOD SAFETY COMPLIANCE RATES}

\section{INTRODUCTION}

Food safety in restaurants is a top public policy issue of 2008 (National Restaurant Association, 2007a). More than 70 billion meals will be eaten outside the home in 2008, with adults consuming an average of about six meals outside the home each week (National Restaurant Association, 2007a). Even meals eaten at home increasingly consist of foods ordered as restaurant take-out (Sloan, 2008).

A large proportion (59\%) of reported foodborne illnesses are traced to foods prepared in restaurants (Centers for Disease Control and Prevention, 2006). With over 13 million people employed in the restaurant industry (National Restaurant Association, 2007a), verifying that employees are following food safety guidelines is an enormous task. Research consistently shows that foodservice establishments are not meeting food safety standards (Food and Drug Administration [FDA], 2000; 2004). In fact, the three factors contributing most significantly to foodborne illnesses (time/temperature abuse, improper hygiene, and cross-contamination) are all related to foodservice employees' noncompliance with food safety guidelines (FDA, 2000; 2004).

Foodservice employees may not comply with food safety guidelines because they are not receiving sufficient training. Food safety training is associated with increased knowledge among foodservice operators (Lynch et al., 2003), and foodservice operators with better restaurant inspection scores have more knowledge and more favorable attitudes about food safety compared to operators with poor inspection scores (Cochran-Yantis et al., 1996). However, food safety knowledge is not always practiced by foodservice employees (Howes et al., 1996). Conclusions 
about the effectiveness of food safety training are difficult to make given that some studies find training is successful at improving behaviors (Cohen et al., 2001; Cotterchio et al., 1998; Kneller and Bierma, 1990; Mathias et al., 1995; McElroy and Cutter, 2004; Roberts et al., in press) and others reported that training was not successful (Casey and Cook, 1979; Howes et al., 1996; Mathias et al., 1994; Wright and Feun, 1986).

Cotterchio et al. (1998) explored the effects of providing a 15-hour foodservice manager training and certification course on the restaurants' routine inspection scores. The training and certification, implemented by the city public health commission, included a group of managers who were invited to participate voluntarily and a group of managers mandated to participate because their license had been suspended due to poor inspection scores or their establishment had been directly linked to incidences of foodborne illness. Improvements in inspection scores resulted and were effective for at least two years after training for both restaurants whose managers were mandated to participate and those who participated voluntarily. Inspection scores of establishments in a control group did not improve. The number of critical violations decreased after training, but the following problems remained: time/temperature abuse, improper sanitization of equipment, and lack of pest management. Kneller and Bierma (1990) investigated restaurant inspection scores prior to and following a 15-hour mandatory food safety training and certification program, and overall inspection scores and critical violations improved following the certification. The improvements were maintained over 18 months.

As a result of reduced microbiological quality of food over a three-month period, a large catering company implemented an in-house training program for managers and employees (Cohen et al., 2001). The eight-hour training was distributed over three sessions within a onemonth period. The training was presented by supervisory managers and was modeled on the 
FDA's Good Manufacturing Practices. Overall microbiological quality of food in the company improved following training, as did the quality of food in departments with the highest risk for contamination (i.e., preparation departments). Although two other departments (portioning and final production) did not show improvements in microbiological quality of the food, the researchers considered the training a success but suggested that future training programs not take a one-size-fits-all approach.

Mathias et al. (1995) observed that restaurants with foodservice managers and employees trained in food safety had better inspection scores than those without trained managers and employees. Also, McElroy and Cutter (2004) identified a 16-hour state-mandated ServSafe ${ }^{\circledR}$ training program to be a success because participants reported being more likely to implement food safety practices after training. Roberts et al. (in press) evaluated the effectiveness of a fourhour ServSafe ${ }^{\circledR}$ training by comparing a group of foodservice employees who had received training with a group who had not. The food safety training improved both knowledge and overall behavioral compliance related to handwashing, use of thermometers, and proper handling of food and work surfaces.

However, not all research has determined food safety training to be effective. In separate studies, Wright and Feun (1986) and Casey and Cook (1979) provided an experimental group with food safety training and certification and found no differences in inspection scores between the experimental group and the control. Mathias et al. (1994) did not find a significant relationship between the number of employees trained in food safety within a restaurant and the restaurants' overall inspection score. Howes et al. (1996) discovered that when foodservice employees were trained, the knowledge did not necessarily lead to improved compliance with food safety practices. 
Pilling et al. (2008) investigated the effects of different types of food safety training requirements on foodservice employees' practices. They compared a group of foodservice employees from restaurants in which food safety training is mandatory for all foodservice employees and a group from restaurants in which only shift managers must be knowledgeable about food safety. The two types of training requirements appeared to contribute a similar amount to employees' knowledge and compliance with handwashing, use of thermometers, and proper handling of food and work surfaces. Because the study did not utilize a control group, no conclusions were made about the effectiveness of these types of training compared to no training.

Several studies have investigated the effectiveness of food safety training. Training imparts knowledge; however, it unfairly assumes that employees will perform these behaviors once training is complete. There are other important contributors to behavior besides knowledge. According to the Theory of Planned Behavior (TpB; Ajzen, 1991), perceived control (i.e., the perception of ability to perform a behavior) is an important contributor to behavior.

Previous research has explored foodservice employees' perceived barriers to food safety (Brannon et al., in press; Green and Selman, 2005; Howells et al., in press; Pilling et al., in press a; Pilling et al., in press b), but no research has focused on improving restaurant employees' perceived control over performing food safety behaviors. Further, research has not attempted to improve the effectiveness of ServSafe ${ }^{\circledR}$ food safety training by the addition of an intervention targeting employees' perceived barriers to food safety. This study sought to address these gaps in the literature and to identify whether an intervention targeting perceived barriers to food safety is effective at increasing restaurant employees' compliance with food safety guidelines. This 
study compared the food safety compliance of restaurant employees in four groups: a group receiving a four-hour ServSafe ${ }^{\circledR}$ training, a group receiving an intervention targeting barriers to food safety, a group receiving both training and intervention, and a control group. The researchers explored the comparative effectiveness of traditional ServSafe ${ }^{\circledR}$ training and a simple intervention targeting barriers to food safety and investigated whether using both treatments is most beneficial for improving compliance with food safety. It was hypothesized that although either the ServSafe ${ }^{\circledR}$ training or the intervention would be better than no treatment, the combination of training and intervention would lead to the most improvements in compliance with food safety behaviors. This study focused on handwashing, use of thermometers, and proper handling of food and work surfaces because these behaviors contribute the most to foodborne illnesses (FDA, 2002; 2004).

Purpose

This study compares the four treatment groups for behavioral compliance with the food safety behaviors and perceived barriers for performing the behaviors. Given that the intervention is easier and less costly to implement than a four-hour food safety training session, it is worthwhile to determine if a simple, low-cost intervention could be as effective as training. Also, it is important to determine whether offering an intervention addressing important barriers to food safety in combination with food safety training will demonstrate increased effectiveness with higher compliance rates for important food safety behaviors and reductions in perceptions of barriers compared to the ServSafe ${ }^{\circledR}$ training alone.

\section{METHODS}

Restaurant employees $(n=368)$, whose jobs involve food preparation tasks, served as participants. Restaurant employees within a 300-mile radius of a large, midwestern university 
were recruited by contacting managers of randomly selected foodservice establishments.

Telephone numbers were obtained from the yellow page directory of restaurants in selected counties in Missouri and from lists of establishments licensed to sell food provided by the Kansas and Iowa state licensing agencies. In exchange for participation, managers were offered free ServSafe ${ }^{\circledR}$ food safety training for their food production employees. Participation included completing a questionnaire assessing beliefs related to specific barriers for performing three food safety behaviors (handwashing, use of thermometers, and proper handling of food and work surfaces) and being observed for behavioral compliance related to these behaviors during peak business hours.

Pilot Tests

Ten focus groups $(n=34)$ conducted with a convenience sample of foodservice employees identified barriers to the three food safety behaviors. Barriers mentioned by at least six of the ten groups were included in the questionnaire (Table 1). The questionnaire was pilot tested on an independent convenience sample $(n=37)$ of foodservice employees to ensure clarity.

\section{Take in Table 1.}

The observation form used to record employees' compliance with the behaviors was pilot tested with all research assistants involved in data collection to ensure adequate inter-rater reliability. The average reliability estimate between two researchers observing the same employees over a three-hour period was .71. 


\section{Questionnaire}

The questionnaire was self-administered and available in English and Spanish. It contained items related to 19 barriers for the food safety behaviors (seven barriers for handwashing, six for use of thermometers, and six for proper handling of food and work surfaces). See Table 1 for a list of barriers included in the questionnaire. These barriers were identified most frequently as barriers to the food safety behaviors during the pilot phase of research (Howells et al., in press; Pilling et al., in press b). This questionnaire assessed beliefs related to each barrier using pairs of items on seven-point scales, for a total of 38 items. Pairs included questions assessing whether participants perceive that the factor makes it more difficult to perform the food safety behavior (i.e., whether they perceive it as a barrier) and questions assessing how often that factor influences their food safety behaviors (i.e., the strength of the barrier). For example, for handwashing, a pair of items was "Not having enough time would make it more difficult to properly wash my hands at work on a regular basis" $(1=$ Strongly Disagree, 7 = Strongly Agree) and "How often does not having enough time affect you properly washing your hands at work?” ( 1 = Very Rarely, 7 = Very Frequently). The questionnaire also included demographic items, including gender, age, and years employed in food production.

\section{Behavioral Observations}

Participants were observed for compliance with the three food safety behaviors. The three broad behavioral categories were broken down into more specific behaviors to observe, including how to perform the behaviors and when to perform them. Table 2 lists all specific behaviors observed. For example, the behaviors for use of thermometers included specific behaviors related to how to take temperatures (e.g., Check internal temperature of food by inserting the thermometer stem or probe into the thickest part of the product) and when to take 
temperatures (e.g., Check temperature of food at the completion of cooking). Behavioral observations lasted for three hours during peak business hours. To avoid observer fatigue, the three-hour observations were separated into six 20 -minute observation periods with 10-minute rest periods between. A research assistant recorded on an observation form when employees performed behaviors correctly and incorrectly. A maximum of four employees were observed simultaneously.

Take in Table 2.

\section{Treatment Groups}

Four groups were compared. The training group received a four-hour ServSafe ${ }^{\circledR}$ food safety training course led by certified ServSafe ${ }^{\circledR}$ instructors before completing the questionnaire and being observed. ServSafe ${ }^{\circledR}$ was developed by the National Restaurant Association Educational Foundation and is considered the national standard in the industry (National Restaurant Association, 2007b). The training session utilized the ServSafe ${ }^{\circledR}$ Employee Guide and supporting materials, which encompass many aspects of food safety other than handwashing, use of thermometers, and proper handling of food and work surfaces. These three behaviors were covered as usual in training rather than being stressed.

The intervention group participated in an intervention program that targeted food safety barriers to reduce employees' perceived barriers so that compliance with these behaviors was increased. The intervention included an incentive program, providing three thermometers to each establishment, and reminder signs for performing the behaviors. Table 3 provides a description of the intervention and barriers targeted. The incentive program involved an employee food safety competition; the employee with the highest percentage of behaviors in 
compliance in each establishment won \$20. Additionally, the small (less than 10 foodservice employees) and the large (more than 10 employees) establishment with the best overall percentage of behaviors in compliance among the foodservice employees won $\$ 75$ and $\$ 100$, respectively. The manager of each establishment was provided with two thermometers a week before the observations, and a third thermometer at the beginning of the observations. The reminder signs were posted one week before the observations and were bright and colorful to attract employees' attention. Each reminder sign was a different color and contained a different statement related to how, when, or why to perform the food safety behaviors. They all began with the question "Did You Know?" because the use of rhetorical questions enhances the processing of messages when the message recipient perceives the message to be of low personal relevance (Petty et al., 1981). In other words, employees who are not involved in their jobs or concerned about the customers' health might be more motivated to process the message when it is presented with rhetorical questions. The signs targeted specific barriers to food safety behaviors, such as not having enough time to wash hands. The sign targeting this barrier stated "Did You Know? Properly washing hands 12 times only takes a total of 4 minutes." Immediately before the observations, the original signs were replaced with signs of different colors to increase novelty and regain the employees' attention, though they retained the same messages. The signs utilized in this intervention are unique from those used in previous research because they were designed to provide reasons why not following the recommended food safety practice might be detrimental to themselves or their employers. The message for each sign is illustrated in Table 4.

Take in Tables 3 and 4. 
The training/intervention group received the four-hour ServSafe ${ }^{\circledR}$ training course and the intervention before completing the questionnaire and being observed. The control group served as a baseline, and these foodservice employees completed the questionnaire and were observed prior to receiving the ServSafe ${ }^{\circledR}$ training course.

\section{RESULTS}

\section{Participants}

Participants $(n=368)$ were in one of four possible treatment groups: training $(n=94)$, intervention $(n=83)$, training/intervention $(n=51)$, or a control group $(n=140)$. Several participants in the control group were originally assigned to one of the three treatment groups. Baseline data was collected on all participants, so if a participant withdrew from the study prior to fully completing participation after their assigned treatment, it was possible to include their baseline data in the study as part of the control group. This explains the unequal treatments groups. Participants were predominantly males (65.5\%). The mean age of participants was 28.8 years, though ages ranged between 15 and 79 years. Participants had been employed in foodservice an average of 8.2 years, but experience ranged from one month to 42 years.

\section{Behavioral Compliance}

A Multivariate Analysis of Variance (MANOVA) was performed on four dependent measures related to compliance with the food safety behaviors. Dependent measures included behavioral compliance with each of the three behaviors separately and a composite index of compliance with the behaviors overall. The dependent measures for each behavioral category were created by combining the behavioral compliance data for all the individual behaviors within that broader behavioral category. The handwashing category compliance index was composed of data from 16 individual behaviors, use of thermometers included data from four individual 
behaviors, and proper handling of food and work surfaces had data from nine individual behaviors. In each instance, the total number of behaviors performed correctly was divided by the total number of behaviors performed, then multiplied by 100 to gain the behavioral compliance percentage. Refer to Table 2 for a list of individual behaviors composing each behavioral category. The overall compliance composite was created by combining all individual behaviors across all behavioral categories; therefore, it was composed of data from 29 individual behaviors. The MANOVA was significant [Wilk's $\Lambda=.63 ; F(12,209)=3.28, p<.001]$. To further investigate the significant effects, a series of four univariate Analyses of Variance (ANOVAs) were performed on the dependent measures (Table 5).

Take in Table 5.

The groups differed in overall behavioral compliance $(p<.001)$. The training/ intervention group, training group, and intervention group all had better behavioral compliance with the food safety behaviors than the control group. The training/intervention group had better overall behavioral compliance than the intervention group. The groups differed in their compliance with handwashing $(p<.001)$. The training/intervention group, training group, and intervention group had better compliance with handwashing than the control group.

The differences between the groups for compliance with use of thermometers approached significance $(p=.059)$. The training/intervention group had better compliance with use of thermometers than the training group and the control group, but not better than the intervention group. The differences between the groups for compliance with proper handling of food and work surfaces also approached significance $(p=.08)$. The training/intervention group was the 
only group that had better compliance with proper handling of food and work surfaces than the control.

\section{Perceived Barriers}

Pairs of composites were calculated for the three behavioral categories and across all behavioral categories to represent 1) the barriers for the behavior(s) targeted in the intervention and 2) the barriers for the behavior(s) not targeted in the intervention. The four pairs of composites were sums of the cross products of the item pairs assessing perceived barriers to the behaviors. Each item pair included an assessment of whether a factor was perceived as a barrier and the strength of the barrier. The cross products of the item pairs representing barriers targeted in the intervention were summed to form one composite for each of the three behaviors and an overall composite across the behaviors. The cross products of the items representing barriers not targeted in the intervention were summed to similarly form another set of composites.

A series of eight univariate ANOVAs were performed to assess differences between the groups for these composites (Table 6). The researchers hypothesized that there would be differences between the groups for the four composites representing barriers targeted in the intervention (indicating the intervention was effective), but no differences between the groups were expected for the composites representing barriers not targeted in the intervention.

Take in Table 6.

For overall barriers related to the food safety behaviors, there were differences between the groups for the composite of barriers targeted in the intervention $(p<.018)$. The training/intervention group perceived more control over the barriers targeted in the intervention 
compared to the training group and the control group. There were no differences between the groups for the composite of barriers not targeted in the intervention.

For handwashing, there were differences between the groups for the composite of barriers targeted in the intervention $(p<.023)$. The training/intervention group and the intervention only group perceived more control related to the barriers targeted in the intervention than did the training group. The training/intervention group was the only group perceiving more control over these barriers than the control group. There were no differences between the groups for the composite of barriers not targeted in the intervention.

For use of thermometers, there were differences between the groups for the composite of barriers targeted in the intervention $(p<.026)$. The training/intervention group perceived more control related to the barriers targeted in the intervention than the training group and the control group. There were no differences between the groups for the composite of barriers not targeted in the intervention.

For proper handling of food and work surfaces, inconsistent with expectations, there were no significant differences between groups for the composite of barriers targeted in the intervention. While the means were in the predicted direction, the differences did not reach significance. Consistent with predictions, there were no differences between the groups for the composite of barriers not targeted in the intervention.

\section{DISCUSSION}

This study compared four treatments: ServSafe ${ }^{\circledR}$ food safety training, an intervention based on the $\mathrm{TpB}$ designed to decrease perceived barriers to performing food safety behaviors, both ServSafe ${ }^{\circledR}$ training and $\mathrm{TpB}$ intervention, and a control. Intervention alone is as effective as 
training alone; however, combining food safety training with the $\mathrm{TpB}$ intervention can offer benefits over training alone.

For behavioral compliance scores, use of thermometers and proper handling of food and work surfaces were more frequently in compliance when employees received the combined ServSafe ${ }^{\circledR}$ training and TpB intervention compared to the control. For use of thermometers, the combined ServSafe ${ }^{\circledR}$ training and TpB intervention group also performed better than the training group. For proper handling of food and work surfaces, the training group performed no better than the control. For handwashing and overall behavioral compliance, all three treatment groups scored higher than the control. For overall behavioral compliance, the training/intervention group also scored higher than the intervention group. In all cases, the intervention group had similar compliance scores to the training group.

For perceived barriers to performing the behaviors, the training/intervention combination is beneficial over training alone for overall perceived barriers to food safety, and perceived barriers specifically related to handwashing and using thermometers. For handwashing, those receiving the intervention alone also perceived more control over barriers than the training group. However, inconsistent with hypotheses, there were no improvements in perceived control over barriers to proper handling of food and work surfaces when foodservice employees received the training/intervention combination compared to training alone. This is most likely due to fewer barriers being targeted in the intervention related to that behavior compared to the other behaviors. It is encouraging that the means for this behavior were in the predicted direction even though they did not reach significance. In fact, the training/intervention group was the only one with positive perceived control over performing behaviors related to proper handling of food and work surfaces. 
The training/intervention combination is effective at improving foodservice employees' perceived control over and compliance with two of the three behaviors investigated. The training/intervention group exhibited better compliance with use of thermometers and proper handling of food and work surfaces, but compliance related to handwashing was similar in all three treatment groups. Possibly, the lack of expected results for handwashing compliance may be explained by the presence of handwashing signs in the restaurants prior to the implementation of our intervention, indicating managers were already attempting to increase foodservice employees' handwashing behaviors with signs posted near handwashing stations as required by the Food Code. While our intervention involved posting bright new signs, it is possible that the novelty of the idea had already diminished among the employees.

One interest was to evaluate whether the simple, relatively inexpensive $\mathrm{TpB}$ intervention could produce similar results to ServSafe ${ }^{\circledR}$ food safety training. ServSafe ${ }^{\circledR}$ training alone and the $\mathrm{TpB}$ intervention alone do offer similar results in terms of both behavioral compliance and perceptions of control over the behaviors. Implementing a simple intervention targeting perceived barriers may prove beneficial for foodservice employees in restaurants in which all employees are not required to attend food safety training. The researchers do not suggest a $\mathrm{TpB}$ intervention be offered in place of ServSafe ${ }^{\circledR}$ training. Results indicate that exposing foodservice employees to both training and intervention produces the best results. Therefore, implementing an intervention targeting perceived barriers also can be helpful in restaurants where foodservice employees are already required to be trained in food safety. Operationally it makes sense that providing employees with both training and the intervention offers more benefits than either alone; these employees should have the knowledge necessary to implement the behaviors, and the intervention may provide the extra reminders and motivation for implementing them. 


\section{Implications}

The results encourage utilizing interventions to reduce perceived barriers to food safety behaviors. Barriers can be targeted in various ways. Earlier phases of research indicated that foodservice employees in restaurants cited the barriers of lack of reminders, not understanding the importance of performing food safety behaviors, lack of incentive to perform the behaviors, lack of time, and lack of thermometers. To address these barriers, the intervention provided signs to assist the employees in remembering to perform the behaviors. The signs also informed employees of the types of serious consequences that can result from not performing the behaviors properly, including death, brain damage, and paralysis for customers or employees; restaurant closure; and loss of employment. Making the employee realize their own life and employment can be affected by not following proper food safety guidelines is an important aspect of the intervention. To do this, the intervention included posting newspaper stories in each establishment about real incidences involving serious foodborne illnesses being traced back to specific restaurants. Posting newspaper clippings about outbreaks in the surrounding area or in well-known restaurant chains may help attract employees' attention.

To target the barrier of lack of incentive to perform the behaviors the intervention implemented a food safety competition between the employees within each establishment, and between the employees at all participating restaurants. Managers can create similar incentive programs to motivate foodservice employees, and the incentive need not be large. Possible incentives include allowing the employee with the best compliance that day or week leave work an hour early with pay, permitting the employee not to perform select tasks, or gifting them with a movie ticket to the local theater or a free meal at the restaurant. While it is not feasible for 
managers to observe employees' compliance with food safety guidelines as was done in this study, they can perform spot checks.

To address the perceived lack of time, a sign was posted to remind employees that 20 seconds is not a long time to spend washing hands by stating that handwashing could be performed 12 times in four minutes. Managers can post signs reminding employees that food safety behaviors are a requirement of their job, rather than distractions from job tasks, and that the behaviors require little time to accomplish (20 seconds for handwashing, and similar lengths of time to take temperatures and sanitize a contaminated surface). The importance of this short amount of time can be compared to the seriousness of consequences that can result if they do not perform the behaviors. This may help demonstrate that the 20 seconds taken to wash hands could save someone's health and save the employee from unemployment.

The intervention also provided establishments with thermometers. Managers need to ensure employees have access to necessary tools that are located in convenient areas in the kitchen. Obviously, if employees do not have access to appropriate supplies (including sinks, soap, paper towels, thermometers, sanitizing solution, and wiping cloths), it is impossible for them to perform food safety behaviors properly.

\section{Conclusion}

Foodservice managers should consider implementing a food safety intervention program in their establishment along with a food safety training program to reduce employees' barriers to food safety. Managers could focus on the barriers targeted in the intervention in this study. It also may be helpful for managers to ask the foodservice employees in their own establishment what they perceive as barriers to performing food safety practices. They could ask employees to anonymously list 1) what makes it more difficult to perform food safety behaviors at work, and 
2) what would make it easier for them to perform specific food safety behaviors. After determining the most frequently listed barriers, the managers can design an intervention to reduce perceived barriers and promote food safety compliance in their establishment. On a larger scale, the current results suggest that it may be beneficial to mandate programs at the state or local level which target employees' perceived barriers to food safety.

\section{Limitations and Future Research}

This research focused on three behaviors that contribute most significantly to foodborne illness. However, food safety encompasses a much broader range of behaviors. Future research could investigate compliance with and perceived barriers to other areas of food safety.

The original response rate for participation was poor. Out of 1,298 restaurant managers contacted for participation, only 31 agreed to allow their employees to participate. Most managers declining participation were uninterested in making the time commitment and allowing researchers into their kitchens. However, given that the manager made the decision to participate, there is no reason to believe that the employees who were allowed to participate were different from the employees whose managers were not willing to participate. The attrition rate was also poor; by the end of data collection, only 16 of the original 31 restaurants remained, hence the unequal treatment group sizes. With such challenges of retaining participants, the power in the analyses also suffered, rendering some of the comparisons nonsignificant.

The current study compared the effectiveness of training and intervention treatments among restaurant employees who were directly involved in food preparation. It is possible foodservice employees in other establishments may require different types of interventions. Future research should be conducted with foodservice employees in child care centers, schools and universities, senior care facilities, and hospitals to determine how best to overcome these 
employees' perceived barriers to food safety and improve compliance with food safety

behaviors. Also, future studies should be conducted with foodservice employees who serve food and are responsible for cleaning and sanitizing as these employees too can affect food quality and safety. 


\section{REFERENCES}

Ajzen, I. (1991), "The theory of planned behavior", Organizational Behavior and Human Decision Processes, Vol. 50, No. 2, pp. 179-211.

Brannon, L. A., Pilling, V. K., Roberts, K. R., Shanklin, C. W., and Howells, A. D. (in press), "Appreciation of food safety practices based on level of experience", Journal of Foodservice Business Research.

Casey, R., and Cook, C. (1979), "Assessment of a food service management sanitation course", Journal of Environmental Health, Vol. 41 No. 5, pp. 281-284.

Centers for Disease Control and Prevention. (2006), "Preliminary FoodNet data on the incidence of infection with pathogens transmitted commonly through food - 10 states, United States, 2005", Morbidity and Mortality Weekly Reports, Vol. 55 No. 14. Available at: http://www.cdc.gov/mmwr/preview/mmwrhtml/mm5514a2.htm. Accessed December $28,2007$.

Cochran-Yantis, D., Belo, P., Giampaoli, J., McProud, L., Everly, V., and Gans, J. (1996), "Attitudes and knowledge of food safety among Santa Clara County, California restaurant operators", Journal of Foodservice Systems, Vol. 9 No. 2, pp. 17-128.

Cohen, E., Reichel, A., and Schwartz, Z. (2001), “On the efficacy of an in-house food sanitation training program: Statistical measurements and practical conclusions", Journal of Hospitality \& Tourism Research, Vol. 25 No. 1, pp. 5-16.

Cotterchio, M., Gunn, J., Coffill, T., Tormey, P., and Barry, M. A. (1998), "Effect of a manager training program on sanitary conditions in restaurants", Public Health Reports, Vol. 113, pp. $353-358$. 
Food and Drug Administration. (2000), "Report of the FDA retail food program database of foodborne illness risk factors.” Available at: http://vm.cfsan.fda.gov/ dms/retrsk.html. Accessed December 28, 2007.

Food and Drug Administration. (2004), "FDA report on the occurrence of foodborne illness risk factors in selected institutional foodservice, restaurant, and retail food store facility types.” Available at: http://www.cfsan.fda.gov/ acrobat/ retrsk2.pdf. Accessed December 28, 2007.

Green, L. R., and Selman, C. (2005), “Factors impacting food workers' and managers' safe food preparation practices: A qualitative study", Food Protection Trends, Vol. 25 No. 12, pp. 981-990.

Howells, A. D., Roberts, K. R., Shanklin, C. W., Pilling, V. K., Brannon, L. A. and Barrett, B. B. (in press), "Restaurant employees' perceptions of barriers to three food safety practices", Journal of the American Dietetic Association.

Howes, M., McEwen, S., Griffith, M., and Harris, L. (1996), "Food handler certification by home study: Measuring changes in knowledge and behavior", Dairy, Food, and Environmental Sanitation, Vol. 16, pp. 737-744.

Kneller, P., and Bierma, T. (1990), "Food service certification measuring the effectiveness of a state program", Journal of Environmental Health, Vol. 52 No. 2, pp. 292-294.

Lynch, R. A., Elledge, B. L., Griffith, C. C., and Boatright, D. J. (2003), “A comparison of food safety knowledge among restaurant managers, by source of training and experience, in Oklahoma County, Oklahoma", Journal of Environmental Health, Vol. 66 No. 2, pp. 914. 
Mathias, R. G., Riben, P. D., Campbell, E., Wiens, M., Cocksedge, W., Hazelwood, A., Kirschner, B., and Pelton, J. (1994), “The evaluation of the effectiveness of routine restaurant inspections and education of food handlers: Restaurant inspection survey", Canadian Journal of Public Health, Vol. 85 Suppl. 1, pp. S61-S66.

Mathias, R. G., Sizio, R., Hazelwood, A., and Cocksedge, W. (1995), “The effects of inspection frequency and food handler education on restaurant inspection violations", Canadian Journal of Public Health, Vol. 86 No. 1, pp. 46-50.

McElroy, D. M., and Cutter, C. N. (2004), "Self-reported changes in food safety practices as a result of participation in a statewide food safety certification program”, Food Protection Trends, Vol. 24 No. 3, pp. 150-161.

National Restaurant Association. (2007a), 2008 Restaurant Industry Forecast, National Restaurant Association, Washington, DC.

National Restaurant Association. (2007b), Total Food Safety Begins with ServSafe ${ }^{\circledR}$ Training and Certification, National Restaurant Association Educational Foundation, Washington, DC. Available at: http://www.servsafe.com/FoodSafety/. Accessed January 23, 2008.

Petty, R. E., Cacioppo, J. T., and Heesacker, M. (1981), “The use of rhetorical questions in persuasion: A cognitive response analysis”, Journal of Personality and Social Psychology, Vol. 40 No. 3, pp. 432-440.

Pilling, V. K., Brannon, L. A., Roberts, K. R., Shanklin, C. W., and Howells, A. D. (in press b), "Using the Theory of Planned Behavior to elicit restaurant employee beliefs about food safety: Using surveys versus focus groups”, Journal of Foodservice Business Research. Pilling, V. K., Brannon, L. A., Shanklin, C. W., Howells, A. D., and Roberts, K. R. (in press a), “Identifying specific beliefs to target to improve restaurant employees' intentions for 
performing three important food safety behaviors", Journal of the American Dietetic Association.

Pilling, V. K., Brannon, L. A., Shanklin, C. W., Roberts, K. R., Barrett, B. B., and Howells, A. D. (2008), “Food safety training requirements and food handlers' knowledge and behaviors", Food Protection Trends, Vol. 28 No. 3, pp. 192-200.

Roberts, K. R., Barrett, B. B., Howells, A. D., Shanklin, C. W., Pilling, V. K., and Brannon, L. A. (in press), "Food safety training and foodservice employees' knowledge and behavior", Food Protection Trends.

Sloan, A. E. (2008), "What, when, and where America eats: State-of-the-industry report", Food Technology, Vol. 62 No. 1, pp. 20-29. Available: http://members.ift.org/NR/rdonlyres/ 60D3BC0D-2113-4C57-BF8D-D5CF36D89E28/0/0108sloan.pdf

Wright, J., and Feun, L. (1986), "Food service manager certification: An evaluation of its impact", Journal of Environmental Health, Vol. 49 No. 1, pp. 12-15. 
Table 1. Barriers Included in the Questionnaire

\begin{tabular}{ll}
\hline Behavior & Barrier to Performing the Behavior \\
\hline Handwashing & \\
\hline & Not having reminder signs \\
& Not having reminders from other employees \\
& Not having the manager monitoring and enforcing the rules \\
& Not having enough time \\
& Not having proper training \\
& Not having enough handwashing sinks \\
& Having the handwashing sinks in an inconvenient location \\
\hline Using Thermometers & Not having reminder signs \\
& Not having the manager monitoring and enforcing rules \\
& Not having enough time \\
& Not having proper training (how to use them and proper \\
& temperatures of food) \\
& Not having enough thermometers \\
& Thermometers being in inconvenient locations \\
\hline Properly Handling Food and Work Surfaces & \\
\hline & Not having reminder signs \\
& Not having the manager monitoring and enforcing rules \\
& Not having enough time \\
& Not having proper training \\
& Not having enough equipment \\
Having the equipment in an inconvenient location
\end{tabular}




\section{Behavior Observed}

\begin{tabular}{l} 
Handwashing \\
\hline Appropriate times \\
Wash hands when starting shift \\
Wash hands when returning to the work area (after smoking, eating, chewing gum or tobacco, bussing tables, \\
or using bathroom) \\
Wash hands before putting on clean gloves \\
Wash hands before and after handling raw food \\
Wash hands after handling chemicals that could contaminate food \\
Wash hands after touching body parts \\
Wash hands after touching clothing/apron \\
Wash hands after touching anything else that may contaminate hands (unsanitized equipment, work surfaces, \\
cleaning cloths, drinking straw) \\
Wash hands when food preparation tasks are interrupted or changed \\
Wash hands after sneezing, coughing, or using a handkerchief/tissue \\
Proper Technique \\
Vigorously scrub hands for at least 20 seconds \\
Vigorously scrub arms above wrists for at least 20 seconds \\
Clean between fingers \\
Clean under fingernails \\
Rinse thoroughly under running water \\
Dry hands and arms with a single-use paper towel or warm-air hand dryer \\
\hline Use of Thermometers \\
\hline Wash, rinse, sanitize, and air-dry before and after use \\
Check internal temperature of food by inserting the thermometer stem or probe into the thickest part of the \\
product \\
Check temperature of food at the completion of cooking \\
Check temperature of food at the completion of reheating \\
Proper Handling of Food and Work Surfaces \\
\hline Food is covered wh
\end{tabular}

Food is covered when transported

Food is covered and labeled properly before holding or storing

Food contact surfaces are free of dust, dirt, and food particles

Leftovers labeled \& dated

Separate raw products from ready-to-eat products

Wiping cloths are stored in a sanitizing solution

Separate wiping cloths are used for food and nonfood surfaces

Wash, rinse, and sanitize food contact surfaces anytime begin working with another type of food or ingredients

Wash, rinse, and sanitize food contact surfaces after touching anything that might contaminate the food-contact surfaces 
Table 3. Description of Intervention Components

\begin{tabular}{|c|c|c|}
\hline Intervention Component & Description & Barriers Targeted \\
\hline Providing Thermometers & $\begin{array}{l}\text { Two thermometers were given to the } \\
\text { manager one week prior to the } \\
\text { observation period. An additional } \\
\text { thermometer was given to the manager } \\
\text { upon arrival for the observation. }\end{array}$ & - Lack of working thermometers \\
\hline Incentive Program & $\begin{array}{l}\text { The employee with the best compliance } \\
\text { in each establishment received a prize of } \\
\$ 20 \text {. The small and large establishments } \\
\text { with the best food safety compliance } \\
\text { overall received } \$ 75 \text { and } \$ 100 \text {, } \\
\text { respectively. }\end{array}$ & $\begin{array}{l}\text { - Lack of incentive to perform the } \\
\text { behaviors }\end{array}$ \\
\hline Persuasive Signs & $\begin{array}{l}\text { Seven signs were posted in high-traffic } \\
\text { kitchen areas, and two newspaper } \\
\text { reports were posted in bathrooms or } \\
\text { break rooms, a week prior to the } \\
\text { observations. Posters were available in } \\
\text { Spanish when necessary. }\end{array}$ & $\begin{array}{l}\text { - Lack of reminder signs } \\
\text { - Lack of understanding the } \\
\text { seriousness of consequences of } \\
\text { not performing the behavior } \\
\text { properly } \\
\text { - Lack of time } \\
\text { - Inconvenience of performing the } \\
\text { behaviors }\end{array}$ \\
\hline
\end{tabular}


Table 4. Exact Wording of Intervention Signs

\begin{tabular}{|c|}
\hline Wording of Intervention Signs \\
\hline $\begin{array}{l}\text { Thousands of bacteria get trapped underneath your fingernails. } \\
\text { Clean under them EVERY time you wash your hands. } \\
\text { Help prevent you and customers from getting sick. } \\
\text { [picture of hands under faucet] }\end{array}$ \\
\hline $\begin{array}{l}\text { Food contaminated due to employees' improper food handling can cause: } \\
\text { DEATH } \\
\text { ILLNESS \& HOSPITALIZATIONS } \\
\text {-Vomiting/Nausea } \\
\text {-Abdominal Cramping } \\
\text {-Bloody Diarrhea } \\
\text {-Fever } \\
\text { LIFELONG MEDICAL PROBLEMS } \\
\text {-Brain Damage } \\
\text {-Kidney Failure } \\
\text {-Blindness } \\
\text {-Paralysis } \\
\text { [picture of hands carrying serving platter] }\end{array}$ \\
\hline $\begin{array}{l}\text { Not practicing good food safety behaviors can: } \\
\text {-make many people very ill } \\
\text {-be traced back to the restaurant (or even you!) } \\
\text {-cause the restaurant to close and you to lose your job } \\
\text { [picture of a "CLOSED" sign] }\end{array}$ \\
\hline $\begin{array}{l}\text { Properly washing hands } 12 \text { times only takes a total of } 4 \text { minutes. } \\
\text { Handwashing helps prevent: } \\
\text {-People getting sick } \\
\text {-Restaurant getting shut down } \\
\text {-You losing your job } \\
\text { [picture of stopwatch; hands under running water] }\end{array}$ \\
\hline $\begin{array}{l}\text { Clean and sanitize work surfaces between preparation tasks so one food cannot contaminate another } \\
\text { and make people sick. } \\
\text { [picture of sanitizer bottle; hand with wiping cloth] }\end{array}$ \\
\hline $\begin{array}{l}\text { The spread of foodborne illness can be avoided when employees properly: } \\
\text {-Wash hands (including under fingernails) } \\
\text {-Check temperatures of food at the end of cooking } \\
\text {-Sanitize work surfaces when contaminated } \\
\text { [picture of hands under running water; steak with thermometer in it; hand with wiping cloth] }\end{array}$ \\
\hline $\begin{array}{l}\text { Relying on touch or sight to decide if food is cooked increases the chances you or a customer will get } \\
\text { sick. } \\
\text { Use a thermometer to check temperatures. } \\
\text { [picture of a roast with a thermometer in it] }\end{array}$ \\
\hline $\begin{array}{l}\text { Two additional signs were made to look like newspaper reports. Each described a separate real-life } \\
\text { case of a customer's experience with foodborne illness after being infected in a restaurant due to food } \\
\text { handler mistakes. These reports were posted in bathrooms and break rooms. }\end{array}$ \\
\hline
\end{tabular}

Note. All signs begin with the question "Did You Know?" 
Table 5. Behavioral Compliance as a Function of Treatment Group $(n=368)$

\begin{tabular}{|c|c|c|c|c|c|}
\hline \multirow[b]{2}{*}{ Behavior } & \multicolumn{4}{|c|}{ Treatment Group } & \multirow[b]{2}{*}{$\begin{array}{c}\text { Test of } \\
\text { Significance }\end{array}$} \\
\hline & $\begin{array}{c}\text { Control } \\
(n=140)\end{array}$ & $\begin{array}{l}\text { Training } \\
(n=94)\end{array}$ & $\begin{array}{l}\text { Intervention } \\
\quad(n=83)\end{array}$ & $\begin{array}{c}\text { Training/ } \\
\text { Intervention } \\
(n=51)\end{array}$ & \\
\hline Handwashing & $31.50 \pm 24.94$ & $46.94 \pm 24.80$ & $43.23 \pm 24.19$ & $52.16 \pm 24.91$ & $F(3,297)=10.57^{\star \star \star}$ \\
\hline $\begin{array}{l}\text { Use of } \\
\text { Thermometers } \\
\text { Proper }\end{array}$ & $16.41 \pm 31.29$ & $18.19 \pm 33.98$ & $22.73 \pm 38.49$ & $44.95 \pm 43.26$ & $F(3,93)=2.57$ \\
\hline $\begin{array}{l}\text { Handling of } \\
\text { Surfaces } \\
\text { Overall }\end{array}$ & $60.98 \pm 32.78$ & $64.85 \pm 32.95$ & $71.21 \pm 34.30$ & $73.99 \pm 28.31$ & $F(3,256)=2.24$ \\
\hline $\begin{array}{l}\text { Behavioral } \\
\text { Composite }\end{array}$ & $37.05 \pm 23.86$ & $47.77 \pm 24.13$ & $46.38 \pm 23.04$ & $56.19 \pm 21.45$ & $F(3,298)=8.77^{\star \star \star}$ \\
\hline $\begin{array}{l}\text { Note. Entries in th } \\
\text { percentages are st } \\
\text { behaviors perform } \\
\text { are test statistics. } \\
\star \star \star * \\
{ }^{2}<.001\end{array}$ & $\begin{array}{l}\text { st four column } \\
\text { of behaviors } \\
\text { correctly and ir }\end{array}$ & $\begin{array}{l}\text { idicate mean } p \\
\text { formed correctl } \\
\text { rectly), then th }\end{array}$ & $\begin{array}{l}\text { entages in comr } \\
\text { ivided by total } n \\
\text { umber was mul }\end{array}$ & $\begin{array}{l}\text { nce } \pm \text { standard } \\
\text { ber of behaviors } \\
\text { ed by } 100 \text {. Entr }\end{array}$ & $\begin{array}{l}\text { viations. Compliance } \\
\text { erformed (sums of the } \\
\text { in the final column }\end{array}$ \\
\hline
\end{tabular}


Table 6. Perceived Control Over Barriers of Food Safety Behaviors as a Function of Group $(n=368)$

\begin{tabular}{|c|c|c|c|c|c|c|}
\hline \multirow[b]{2}{*}{ Behavior } & \multirow[b]{2}{*}{$\begin{array}{c}\text { Barriers } \\
\text { Targeted or } \\
\text { Not Targeted }\end{array}$} & \multicolumn{4}{|c|}{ Treatment Group } & \multirow[b]{2}{*}{$\begin{array}{c}\text { Test of } \\
\text { Significance }\end{array}$} \\
\hline & & $\begin{array}{c}\text { Control } \\
(n=140)\end{array}$ & $\begin{array}{l}\text { Training } \\
(n=94)\end{array}$ & $\begin{array}{l}\text { Intervention } \\
\quad(n=83)\end{array}$ & $\begin{array}{c}\text { Training/ } \\
\text { Intervention } \\
(n=51)\end{array}$ & \\
\hline \multirow{2}{*}{ Handwashing } & Targeted & $-1.25 \pm 19.85$ & $-3.77 \pm 20.39$ & $3.75 \pm 10.41$ & $6.68 \pm 13.22$ & $F(3,236)=3.25^{\star}$ \\
\hline & Not Targeted & $3.00 \pm 15.52$ & $0.04 \pm 15.15$ & $2.22 \pm 10.47$ & $4.90 \pm 10.18$ & $F(3,240)=1.16$ \\
\hline Use of & Targeted & $-6.65 \pm 20.78$ & $-9.66 \pm 16.79$ & $-5.34 \pm 11.90$ & $1.13 \pm 11.06$ & $F(3,238)=3.14^{\star}$ \\
\hline Thermometers & Not Targeted & $-3.63 \pm 20.75$ & $-2.44 \pm 17.87$ & $-1.61 \pm 12.35$ & $0.47 \pm 11.20$ & $F(3,238)=0.44$ \\
\hline Proper Handling of & Targeted & $-1.63 \pm 10.42$ & $-1.40 \pm 10.03$ & $-0.09 \pm 7.99$ & $1.78 \pm 7.62$ & $F(3,241)=1.16$ \\
\hline Surfaces & Not Targeted & $-3.95 \pm 19.22$ & $-5.58 \pm 17.60$ & $-2.88 \pm 11.04$ & $-0.94 \pm 14.84$ & $F(3,239)=0.65$ \\
\hline Overall Behavioral & Targeted & $-9.70 \pm 44.79$ & $-15.51 \pm 39.86$ & $-2.32 \pm 21.63$ & $9.10 \pm 26.85$ & $F(3,226)=3.42^{\star}$ \\
\hline Composite & Not Targeted & $-3.82 \pm 46.17$ & $-6.08 \pm 41.84$ & $0.19 \pm 24.73$ & $2.97 \pm 29.17$ & $F(3,228)=0.47$ \\
\hline
\end{tabular}

Note. Entries in the first four columns are means \pm standard deviations. Negative means indicate a perception of not being in control of the performing the

behavior, while a positive entry indicates a perception of control. Entries in the final column are test statistics.

$\star p<.05$ 
